\title{
natureINSIGHT
}

\section{ORIGIN AND EVOLUTION OF VERTEBRATES}

23 April 2015 / Vol 520 / Issue No 7548

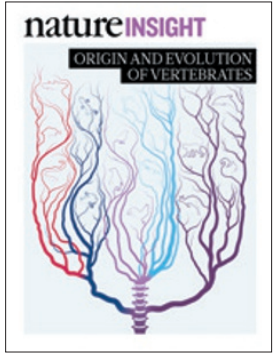

Cover illustration Jasiek Krzysztofiak

Editor, Nature

Philip Campbell

Publishing

Richard Hughes

Production Editor

Jenny Rooke

Art Editor

Nik Spencer

Sponsorship

Reya Silao

Production

Emilia Orviss

Marketing

Steven Hurst

Editorial Assistant

Melissa Rose

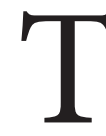

To celebrate the golden jubilee of On the Origin of Species, in 1909, the Linnean Society of London held a special meeting on a hot biological topic of the day - the origin of the vertebrates. Such was the lack of consensus that one commentator, the zoologist T. R. R. Stebbing, wrote that "the disputants agreed on one single point, namely, that their opponents were all in the wrong."

The problem is easily stated - vertebrates have so many special features, from large brains to complex physiologies to unique tissues such as enamel and bone - that their evolution from invertebrates is obscure. The question had intrigued Aristotle, and foxed minds as keen as those of William Bateson and Thomas Hunt Morgan, who, by way of finding a more rewarding problem, went off to discover genetics instead.

The same tools that Bateson and Hunt Morgan helped to create have now returned to address the old problem. Although our understanding is far from complete, it is much better than it was even 20 years ago, and is summarized in this collection of reviews.

Nicholas Holland and colleagues set out how the varied theories advanced to explain vertebrate origins, before Lowe et al. show how they fit in to the deuterostomes, a larger branch of the animal kingdom. Diogo et al. add new perspectives to a central question of vertebrate origins, namely, the origin of the head. Marianne Bronner and colleagues then look at the embryonic tissue known as neural crest, another uniquely vertebrate feature. Philippe Janvier surveys the wealth of newly found, and often curious, fossil evidence, and Martin Brazeau and Matt Friedman chart the evolution of jawed vertebrates from jawless forms. If Stebbing was able to peruse this collection, I hope he would agree that we have come a long way.

\section{Henry Gee \\ Senior Editor}

\section{CONTENTS}

\section{REVIEWS}

450 Scenarios for the making of vertebrates

Nicholas D. Holland, Linda Z. Holland \& Peter W. H. Holland

456 The deuterostome context of chordate origins

Christopher J. Lowe, D. Nathaniel Clarke, Daniel M. Medeiros, Daniel S. Rokhsar \& John Gerhart

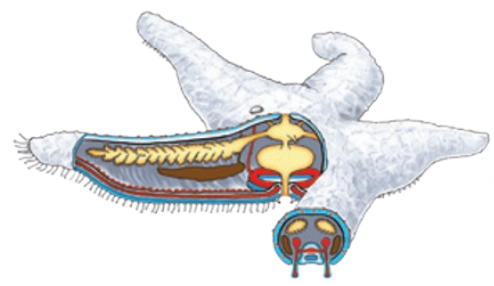

466 A new heart for a new head in vertebrate cardiopharyngeal evolution

Rui Diogo, Robert G. Kelly, Lionel Christiaen, Michael Levine, Janine M. Ziermann, Julia L. Molnar, Drew M. Noden \& Eldad Tzahor

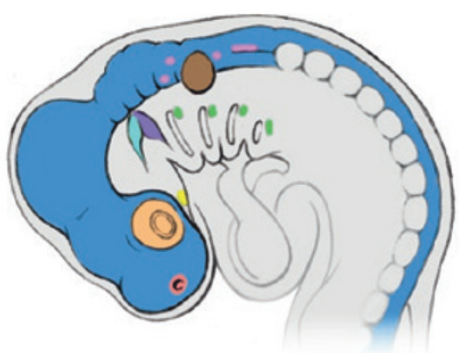

474 Evolution of vertebrates as viewed from the crest Stephen A. Green, Marcos Simoes-Costa \& Marianne E. Bronner

483 Facts and fancies about early fossil chordates and vertebrates Philippe Janvier

490 The origin and early phylogenetic history of jawed vertebrates Martin D. Brazeau \& Matt Friedman 